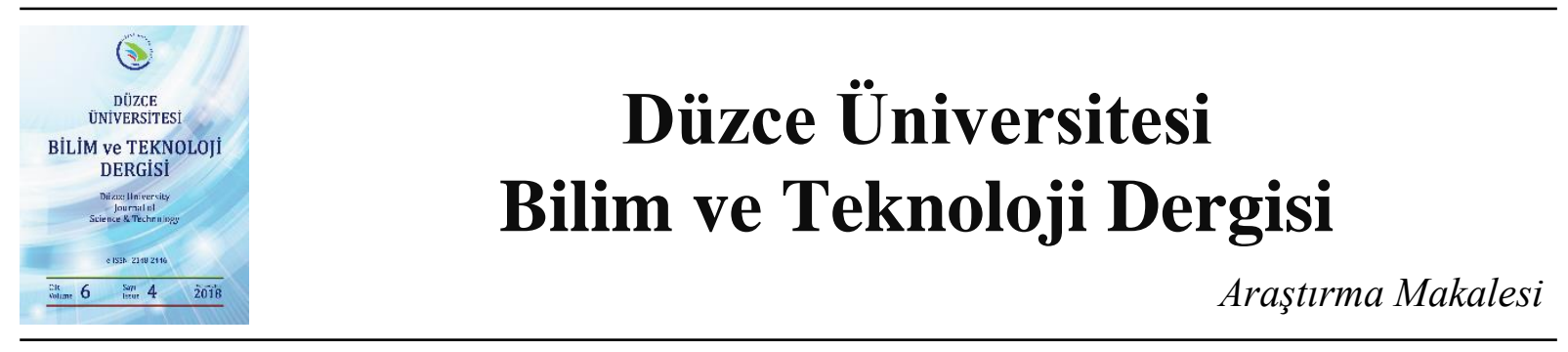

\title{
AA7075-T6 Alaşımının Farklı Sıcaklıklardaki Çekme Davranışının Deneysel ve Nümerik Yöntemler ile İncelenmesi
}

M. Hüseyin ÇETIN ${ }^{\text {a,*}}$, Şeyma KORKMAZ ${ }^{\text {a }}$, Mehmet Emin ÇETIN ${ }^{\text {b }}$, Mohamed Ali Emhmed BELRZAEG ${ }^{\text {a }}$

${ }^{a}$ Makine Mühendisliği Bölümü, Mühendislik Fakültesi, Karabük Üniversitesi, Karabük, TÜRKIYYE

${ }^{b}$ Uzay ve Uydu Mühendisliği Bölümü, Havacılık ve Uzay Bilimleri Fakültesi, Necmettin Erbakan Üniversitesi, Konya, TÜRKIYE

* Sorumlu yazarin e-posta adresi: hcetin@karabuk.edu.tr

\begin{abstract}
ÖZET
$\mathrm{Bu}$ çalışmada, AA7075-T6 alaşımının oda sıcaklığındaki ve $100{ }^{\circ} \mathrm{C}, 150{ }^{\circ} \mathrm{C}, 200{ }^{\circ} \mathrm{C}, 250{ }^{\circ} \mathrm{C}$ ve $300{ }^{\circ} \mathrm{C}$ sıcaklıklardaki çekme davranışı deneysel, fragtografik ve nümerik olarak incelenmiştir. Deneysel olarak elde edilen akma $\left(\sigma_{\mathrm{a}}\right)$ ve çekme $\left(\sigma_{\zeta}\right)$ mukavemeti ile birim şekil değiştirme değerlerinin $(\varepsilon)$ sıcaklık değişimine bağlı değişimi grafiksel ve istatistiksel olarak incelenmiştir. Deneysel verilerin nümerik analizi için Piecewise malzeme modeli kullanılmıș ve renk analizi yöntemi ile gerilme dağılımları incelenmiștir. Fragtografik analiz için deformasyon bölgelerinin SEM görüntüleri incelenmiş, oda sıcaklığı, $100{ }^{\circ} \mathrm{C}, 150{ }^{\circ} \mathrm{C}$ sıcaklıklarda tane içi kırılma, $200{ }^{\circ} \mathrm{C}, 250$ ${ }^{\circ} \mathrm{C}$ ve $300{ }^{\circ} \mathrm{C}$ sıcaklıklarda tane sinırlarında kırılma meydana geldiği görülmüştür. Deneysel veriler genel olarak değerlendirildiğinde; $100{ }^{\circ} \mathrm{C}$ sıcaklığa kadar malzemenin mekanik özeliklerinde değişiklik görülmemiş, $100{ }^{\circ} \mathrm{C}-$ $250^{\circ} \mathrm{C}$ aralığında malzemenin sünekliği artmış, akma ve çekme mukavemetleri belirli bir oranda azalmış, sıcaklık $300{ }^{\circ} \mathrm{C}$ 'ye ulaştığında ise akma ve çekme mukavemetinde yüksek oranda azalma meydana gelmiştir.
\end{abstract}

Anahtar Kelimeler: AA7075-T6, Çekme deneyi, Fragtografik Analiz, Nümerik Analiz

\section{Examination with Experimental and Numerical Methods of Tensile Behavior of AA7075-T6 Alloy at Different Temperatures}

\begin{abstract}
$\underline{\text { ABSTRACT }}$
In this study, tensile behaviour of AA7075-T6 alloy at room temperature and at temperatures of $100{ }^{\circ} \mathrm{C}, 150{ }^{\circ} \mathrm{C}, 200$ ${ }^{\circ} \mathrm{C}, 250{ }^{\circ} \mathrm{C}$ and $300{ }^{\circ} \mathrm{C}$ was investigated experimentally, by using fragtographic results and numerically. The alteration of experimentally obtained values of yield $(\sigma a)$ and tensile $(\sigma c ̧)$ stresses with strain parameter $(\varepsilon)$ according to the temperature was investigated graphically and statistically. For the numerical analysis of the experimental data, Piecewise material model was used and stress distributions were examined by colour analysis method. For fragtographic analysis, SEM images of deformation zones were investigated and it was observed that the transgranular fracture was occurred at room temperature, $100{ }^{\circ} \mathrm{C}$ and $150{ }^{\circ} \mathrm{C}$ temperatures, and intergranular fracture was occurred at $200{ }^{\circ} \mathrm{C}, 250{ }^{\circ} \mathrm{C}$ and $300{ }^{\circ} \mathrm{C}$ temperatures. When the experimental results are evaluated in general, the mechanical properties of the material are not changed up to $100{ }^{\circ} \mathrm{C}$. The material ductility increased,
\end{abstract}


and the yield and tensile strengths decreased at a certain rate between $100{ }^{\circ} \mathrm{C}$ and $250{ }^{\circ} \mathrm{C}$. When the temperature reaches $300^{\circ} \mathrm{C}$, the flow and tensile strength decrease at a high rate.

Keywords: AA7075-T6, Tensile Test, Fragtographic Analysis, Numeric Analysis

\section{GiRiș}

$\mathrm{E}$ nerji tasarrufu amaçlı endüstriyel uygulamalardan bir tanesi de alüminyum (Al) ve magnezyum $(\mathrm{Mg})$ hafif alaşımlarının konstrüktif uygulamalarda kullanımıdır. Düşük yoğunluğuna rağmen, oda sıcaklığında paslanmaz çelik malzeme kadar dayanım sergileyen 7XXX serisi Al alaşımları mühendislik uygulamalarında dikkat çeken alternatiflerden birisi olmaktadır. 7XXX serisi alüminyum (Al) alaşımları \% 4-8 oranında $\mathrm{Zn}$ ve \% 1-3 oranında $\mathrm{Mg}$ içermektedir [1, 2, 3]. Çinko ve magnezyum elementlerinin $\mathrm{Al}$ içerisinde yüksek oranda çözülebilmesi, 7XXX serisinin yüksek dayanım özelliği kazanmasını sağlamaktadır [1]. Fakat artan dayanım ile birlikte süneklikte düşmektedir [4]. Bu durum 7XXX serisi Al alaşımlarının oda sıcaklığında şekillendirilebilirliğini kısıtlamaktadır. Spesifik mukavemeti $\left(\sigma_{a} / \rho_{A l}\right)$ yüksek olması sebebiyle kritik mühendislik yapılarında yoğun kullanım alanına sahip [2] olan 7XXX serisi Al alaşımlarının şekillendirilebilirliklerinin arttırılması, şekillendirme işleminin yüksek sıcaklıklarda gerçekleştirilmesi ile sağlanabilir. İç yapıyı değiştirmeden şekillendirilebilirliğin arttırıldığı limit sıcaklık kademesi ise yeniden kristalleşme sıcaklığ değerleridir ( $\left.\approx 0,3 . T_{\text {erime }}\right)$ [2]. Bu değer 7XXX serisi Al alaşımları için $300{ }^{\circ} \mathrm{C}$ olarak dikkate alınabilir. Yüksek sıcaklıkta malzemelerin mekanik özelliklerinin değişmesi sebebiyle, şekillendirme işlemi ve malzemenin kullanım yerindeki sıcaklık değerlerine bağlı olarak mekanik özelliklerin bilinmesi gerekmektedir. Farklı sıcaklıklardaki mekanik davranışın deneysel olarak elde edilmesi zaman, maliyet ve ekipman kısıtları sebebiyle her zaman mümkün olmayabilir. Bu sebeple nümerik analiz yöntemiyle mekanik davranışın tespit edilmesi mühendislik açısından önem taşımaktadır. Mekanik davranışı doğru olarak tespit edebilmek malzeme parametrelerinin doğru seçilmesi, analiz edilecek bölgenin yeteri kadar alt elemanlara bölünmesi ve doğru koordinatlara doğru kuvvet yüklemelerinin yapılabilmesi ile mümkündür. Çok sayıda faktörün nümerik analiz sonuçları üzerinde etkisi olması sebebiyle, deneysel olarak doğrulanmış nümerik model sonuçlarının elde edilmesi önemlidir.

Bobbili ve arkadaşları [5], farklı sıcaklıklarda ve gerinim oranlarında Johnson-Cook (J-C modeli) malzeme modelini 7017 alüminyum alaşımı için geliştirerek gerilme davranışını araştırmışlardır. Giriş parametresi olarak; 0.01, 500, 1000 ve $1500 \mathrm{~s}^{-1}$ şekil değiştirme hız değerleri ve $25,100,200$ ve $300{ }^{\circ} \mathrm{C}$ sıcaklıkları kullanılmış, çıkış parametresi olarak da çekme mukavemetleri incelenmiştir. Yapılan çekme deneyleri ve geliştirilen J-C modeli karşılaştırıldığında, J-C modelinin deneysel verileri sadece ara sıcaklıklarda doğru tahmin edebildiği görülmüştür. Çalışmada elde edilen sonuçlar ara sıcaklık değerleri için anlamlı olsa da malzemelerin özellikle yüksek sıcaklıklarda deformasyona uğradıkları göz önüne alındığında geliştirilen J-C modelinin, 7017 alüminyum alaşımının mukavemet incelemesi için yeterli olmadığ1 görülmüştür. Chen ve arkadaşları [6], 7075 alüminyum alaşımının mukavemetini çekme deneyi ve sonlu eleman analizi ile incelemişlerdir. Çalışmada giriş parametresi olarak 7075 alüminyum alaşımının çekme testi ve hasar indeksi verileri dikkate alınmış, çıkış parametresi olarak kırılma yüzeyinin sonlu elemanlar yöntemiyle benzetilebilirliği incelenmiştir. Li ve arkadaşları [7], üç farklı alüminyum alaşımının (Al 5182 + Mn, Al 5754 ve Al 6111- T4) 1lık şekillendirme sıcaklık aralığında 
çekme deformasyon davranışını incelemiştir. Giriş parametresi olarak $200-350^{\circ} \mathrm{C}$ sıcaklık aralığ ve 0.015 - $1.5 \mathrm{~s}^{-1}$ şekil değiştirme hız aralığı dikkate alınmış, çıkış parametresi olarak çekme mukavemeti incelenmiştir. Çalışmada yüzde uzamanın sıcaklık arttıkça arttığı, şekil değiştirme hızı arttıkça azaldığ1 görülmüştür. Hu ve arkadaşları [8], farklı sıcaklıklarla yapılan çekme testleri ile 7050 alüminyum alaşımının deformasyon davranışını ve mikroyapı incelemesi ile malzemenin iç yapısındaki değişimi araştırmıştır. Giriş parametresi olarak $340,380,420,460^{\circ} \mathrm{C}$ sıcaklık değerleri ve $10^{-4}, 10^{-3}, 10^{-2}$ ve $10^{-1}$ şekil değiştirme hızları kullanılmış, çıkış parametresi olarak giriş parametrelerinin deformasyona etkileri araştırılmıştır. Yapılan araştırmada 7050 alüminyum alaşımının çekme mukavemetinin, yüksek sıcaklık deformasyonu süresi boyunca sıcaklık arttıkça ve şekil değiştirme hızı azaldıkça azaldığı sonucu elde edilmiştir. Rokni ve arkadaşları [3], 7075-T6 alüminyum alaşımının deformasyon davranışı ve mikroyapı özelliklerini farklı sıcaklık ve şekil değiştirme hızlarında sıcak basma deneyi uygulayarak araştırmışlardır. Deneyde giriş parametresi olarak $450,500,520,550,580^{\circ} \mathrm{C}$ sıcaklıkları ve $0.004,0.04$ ve 0.4 şekil değiştirme hızları kullanılmış, çıkış parametresi olarak basma mukavemeti incelenmiştir. Çalışma sonucunda maksimum basma gerilmesi değerinin deformasyon sıcaklığının azalması ve şekil değiştirme hızının artmasıyla arttı̆ğ görülmüştür.

$\mathrm{Bu}$ çalışmanın özgün değeri, AA7075-T6 alüminyum alaşımının oda sıcaklığındaki ve $100{ }^{\circ} \mathrm{C}, 150{ }^{\circ} \mathrm{C}$, $200{ }^{\circ} \mathrm{C}, 250^{\circ} \mathrm{C}$ ve $300{ }^{\circ} \mathrm{C}$ sıcaklıklardaki çekme davranışının deneysel ve nümerik olarak incelenmesidir. Literatürde AA7075-T6'nın sadece $450^{\circ} \mathrm{C}$ ve üzeri sıcaklıklardaki mekanik davranışları incelenmiştir. $\mathrm{Bu}$ çalışmada ise yeniden kristalleşme sıcaklığı altındaki değerler için mekanik davranışı analiz edilmiştir. Çekme testi sonucu deforme olan yüzeylerin SEM görüntüleri alınarak malzemenin farklı sıcaklıklardaki deformasyon davranışı görsel olarak değerlendirilmiştir. Çalışmanın nümerik kısmında ise, farklı sıcaklıklardaki mekanik davranışın sonlu elemanlar yöntemi ile bilgisayar ortamında benzetilebilirliği analiz edilmiştir.

\section{MALZEME VE METOT}

Deneylerde kullanılan AA7075-T6 alaşımının kimyasal kompozisyonu Tablo 1'de verilmiştir. Oda sıcaklığında çekme testine tabi tutulan numune TS 138 EN 10002-1 (Şekil 1) standartlarında, $100{ }^{\circ} \mathrm{C}$ ve üstü sıcaklıklarda çekme testine tabi tutulan numuneler ise ASTM E21 (Şekil 2) standartlarına göre hazırlanmıştır. Çekme testi, oda sıcaklığ 1 ve $300^{\circ} \mathrm{C}$ 'ye kadar olan sıcaklık kademeleri için Zwick/Roell Z600 Universal Test Cihazı kullanılarak TS EN ISO 6892-1 standardına uygun olarak gerçekleştirilmiştir. Deneysel hataların minimizasyonu için her bir çekme deneyi 3 tekrarlı olarak yapılmıştır. Deney parametreleri Tablo 2'de verilmiştir. Tablo 2'ye göre oda sıcaklığı, $100{ }^{\circ} \mathrm{C}, 150{ }^{\circ} \mathrm{C}$, $200{ }^{\circ} \mathrm{C}, 250{ }^{\circ} \mathrm{C}, 300{ }^{\circ} \mathrm{C}$ sicaklıklarda, $0,001 \mathrm{~s}^{-1}$ şekil değiştirme hızında deneyler gerçekleştirilmiştir. Şekil değiştirme süresinin hesabında ortalama şekil değiştirme süresi dikkate alınmış olup, " $\varepsilon / \tilde{\varepsilon}$ " ( $\varepsilon$ : Birim şekil değiştirme, $\dot{\varepsilon}$ : Şekil değiştirme hızı) bağıntısı ile süre hesabı yapılmıştır. Deformasyona uğramış kesitlerin görüntüleri Carl Zeiss marka SEM mikroskobu kullanılarak elde edilmiştir.

Tablo 1. AA7075- T6 alaşımının kimyasal bileşimi

\begin{tabular}{lllllllllc}
\hline Element & $\mathrm{Al}$ & $\mathrm{Zn}$ & $\mathrm{Mg}$ & $\mathrm{Cu}$ & $\mathrm{Fe}$ & $\mathrm{Mn}$ & $\mathrm{Ti}$ & $\mathrm{Cr}$ & $\mathrm{Si}$ \\
\hline $\begin{array}{l}\text { Yüzde } \\
\text { Ăğırlığı }\end{array}$ & 88,86 & 6,08 & 2,70 & 1,32 & 0,2 & 0,1 & 0,17 & 0,24 & 0,33 \\
\hline
\end{tabular}


AA7075-T6 alaşımı için oda sıcaklığında ve $100{ }^{\circ} \mathrm{C}, 150{ }^{\circ} \mathrm{C}, 200{ }^{\circ} \mathrm{C}, 250{ }^{\circ} \mathrm{C}, 300{ }^{\circ} \mathrm{C}$ sicaklıklarda gerçekleştirilen çekme deneyleri Ls DYNA sonlu elemanlar yazılımı ile sayısal olarak modellenmiştir. $\mathrm{Bu}$ amaçla oda sıcaklığı ve yüksek sıcaklık çekme numuneleri katı model olarak Solidworks programında çizilmiştir. Daha sonra bu katı modeller Hypermesh ortamına parasolid (.x_t) formatında aktarılmıştır. Oda sıcaklığı ve yüksek sıcaklık çekme numuneleri için Tablo 3'de gösterilen 3 farklı eleman sayısında sonlu eleman ağ örgüsü oluşturulmuştur. 3 boyutlu 8 düğüm noktalı yapısal katı tipi quadratic eleman sonlu eleman tipi olarak seçilmiştir. Analizlerde (açık adım) explicit çözüm tekniği kullanılmıştır. Oluşturulan 6 farklı model Ls-Dyna sonlu elemanlar yazılımı ortamında çekme deneyinin birebir modellenmesi için; çekme deneyinde ki sınır şartları, çekme hızı, deneyin yapıldığı sıcaklık değeri kartlara sayısal olarak girilmiştir. Yüksek sıcaklık çekme deneyleri için oluşturulan sonlu elemanlar modeli ve sınır şartları Şekil 3'de gösterilmiştir. Çekme deneylerinden elde edilen gerilme-şekil değiştirme diyagramları gerçek gerilme- gerçek şekil değiştirme diyagramlarına dönüştürülmüştür. Bununla birlikte, bu eğriler Piecewise lineer plastisite malzeme modeline girilmiş ve bu yolla çekme deneyleri sayısal olarak modellenmiştir. Piecewise malzeme modeline AA7075-T6 alaşımının yoğunluğu $2.81 \mathrm{~g} / \mathrm{cm}^{3}$, poisson oran 0,33 ve elastisite modülü $71,7 \mathrm{GPa}$ olarak girilmiştir.

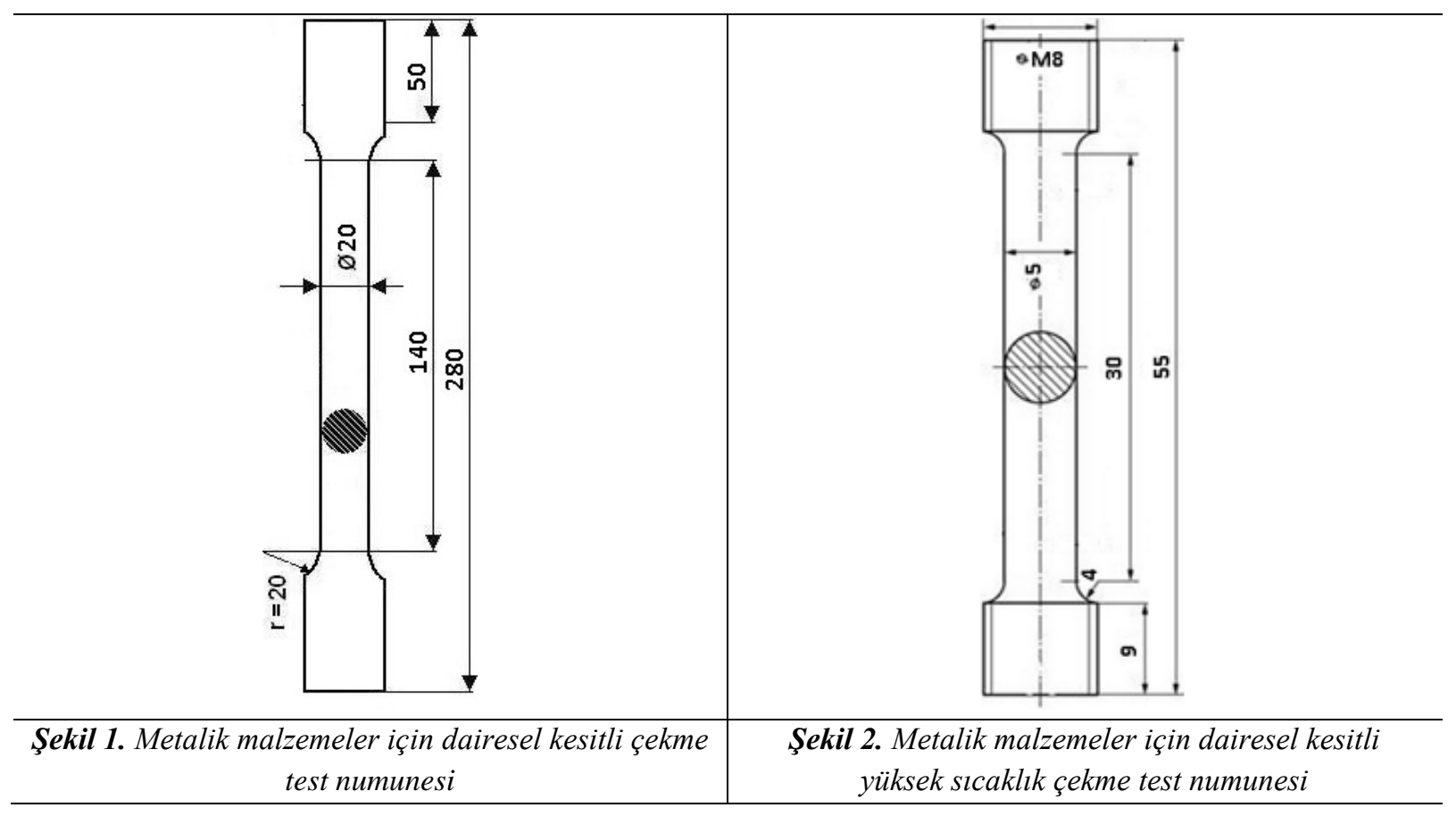

Tablo 2. Deney Parametreleri

\begin{tabular}{|c|c|c|}
\hline $\begin{array}{c}\text { Şekillendirme Sıcaklığı } \\
\left({ }^{\circ} \mathrm{C}\right)\end{array}$ & $\begin{array}{c}\text { Şekil Değiştirme Hızı } \\
\left(\mathrm{s}^{-1}\right)\end{array}$ & $\begin{array}{c}\text { Şekillendirme Süresi } \\
\text { (s) }\end{array}$ \\
\hline Oda sıcaklığ 1 & \multirow{6}{*}{0,001} & 108 \\
\hline 100 & & 108 \\
\hline 150 & & 149 \\
\hline 200 & & 150 \\
\hline 250 & & 152 \\
\hline 300 & & 151 \\
\hline
\end{tabular}


Tablo 3. Oluşturulan modellerdeki eleman sayıları

\begin{tabular}{cccc}
\hline & \multicolumn{3}{c}{ Eleman Sayıs1 } \\
\cline { 2 - 4 } & $\mathrm{Az}$ & Orta & İyi \\
\hline Oda Sicaklığ1 & 3132 & 26169 & 57000 \\
\hline Yüksek Sicaklık & 6156 & 20196 & 34917 \\
\hline
\end{tabular}

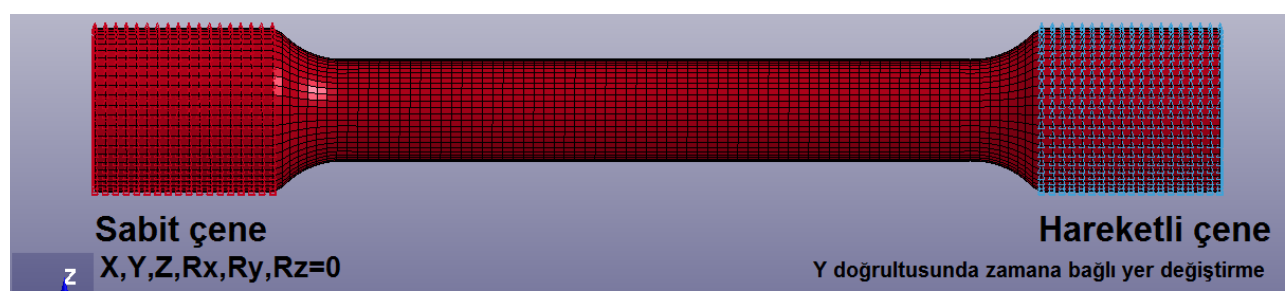

Şekil 3. Sonlu elamanlar modeli

\section{TARTISMA VE SONUC}

\section{A. ÇEKME TESTI}

AA7075-T6 alüminyum alaşımının mekanik özelliklerinin analizi için farklı sıcaklıklarda çekme testleri gerçekleştirilmiştir. Çekme testlerine ait çekme diyagramları ve deforme olmuş numunelerin görüntüleri Tablo 4'te verilmiştir. Çekme diyagramları incelendiğinde malzemenin düşük sıcaklıklarda gevrek (Oda sıcaklığ ve $100{ }^{\circ} \mathrm{C}$ için $\left.\varepsilon \leq 0,12\right)$, yüksek sıcaklıklarda sünek kırılmaya $\left(150^{\circ} \mathrm{C}\right.$ ve üzeri sıcaklıklar için $\varepsilon \geq 0,15)$ maruz kaldığı görülmüştür. $250{ }^{\circ} \mathrm{C}$ 'ye kadar gerçekleştirilen deneylerde, AA7075-T6 malzemenin akma ve çekme dayanımlarında sıcaklık artışı ile anlamlı bir azalma oranı gözlenirken (\%10-\%20), $250-300^{\circ} \mathrm{C}$ arasında akma-çekme dayanımı azalma oranı yaklaşık \%50 oranında gerçekleşmiştir. $\mathrm{Bu}$ durum $250{ }^{\circ} \mathrm{C}$ 'den sonra yeniden kristalleşme davranışının daha fazla etkili olmasıyla açıklanabilir. Yeniden kristalleşme sürecinde tane boyutu büyümesi sebebiyle birim hacme düşen tane sınırı miktarı azalacaktır. Azalan tane sınırından dolayı dislokasyonlarda meydana gelecek kayma hareketi kolaylaşarak malzemenin akma ve çekme dayanımının düşmesine sebep olacaktır. Oda sıcaklığından $250{ }^{\circ} \mathrm{C}$ 'ye kadar olan sıcaklık artışı ile akma-çekme dayanımının azalması durumu ise malzeme içinde bulunan kayma bantlarının sıcaklık etkisine bağlı olarak aktif hale gelmesi ile açıklanabilir [9]. Dislokasyonlar kayma bantları üzerinden daha rahat hareket edebileceği için malzemenin akma-çekme değerlerinde de azalma gözlenmiştir. Ayrıca Tablo 4'e göre $100{ }^{\circ} \mathrm{C}, 150{ }^{\circ} \mathrm{C}$ ve $200^{\circ} \mathrm{C}$ sicaklıklarda malzeme oda sicaklığına göre daha yüksek rezilyans değeri göstermiştir. $250^{\circ} \mathrm{C}$ ve $300{ }^{\circ} \mathrm{C}$ değerlerinde ise $\sigma_{\text {akma }}$ değeri çok düşmektedir. Bu durum malzemenin $100{ }^{\circ} \mathrm{C}, 150{ }^{\circ} \mathrm{C}$ ve $200{ }^{\circ} \mathrm{C}$ ' de $250^{\circ} \mathrm{C}$ ve $300^{\circ} \mathrm{C}$ 'ye nazaran daha elastik davranış sergileyeceğini göstermektedir. 
Tablo 4. Çekme testlerine ait çekme diyagramlarl ve deforme olmuş numunelerin görüntüleri

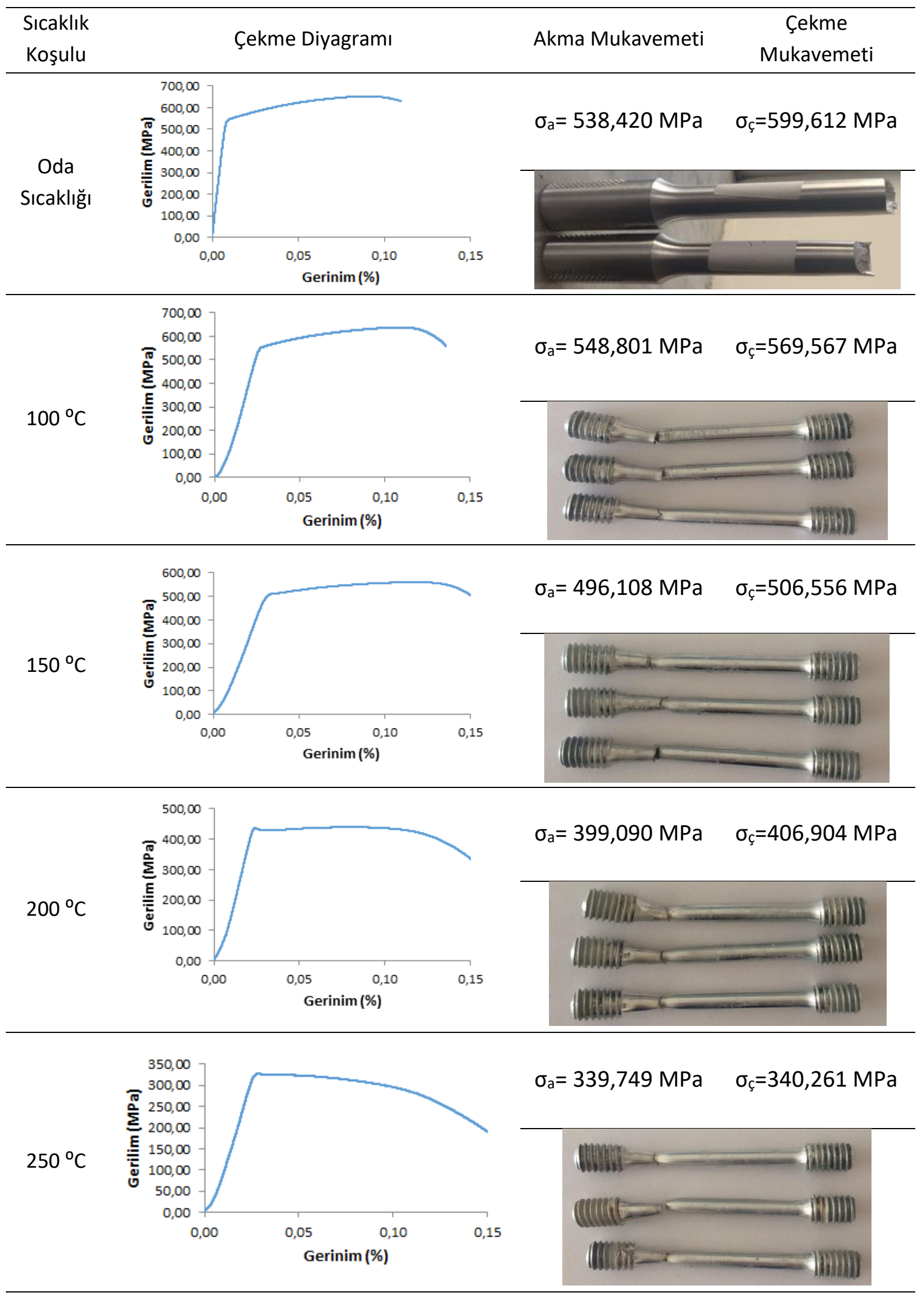




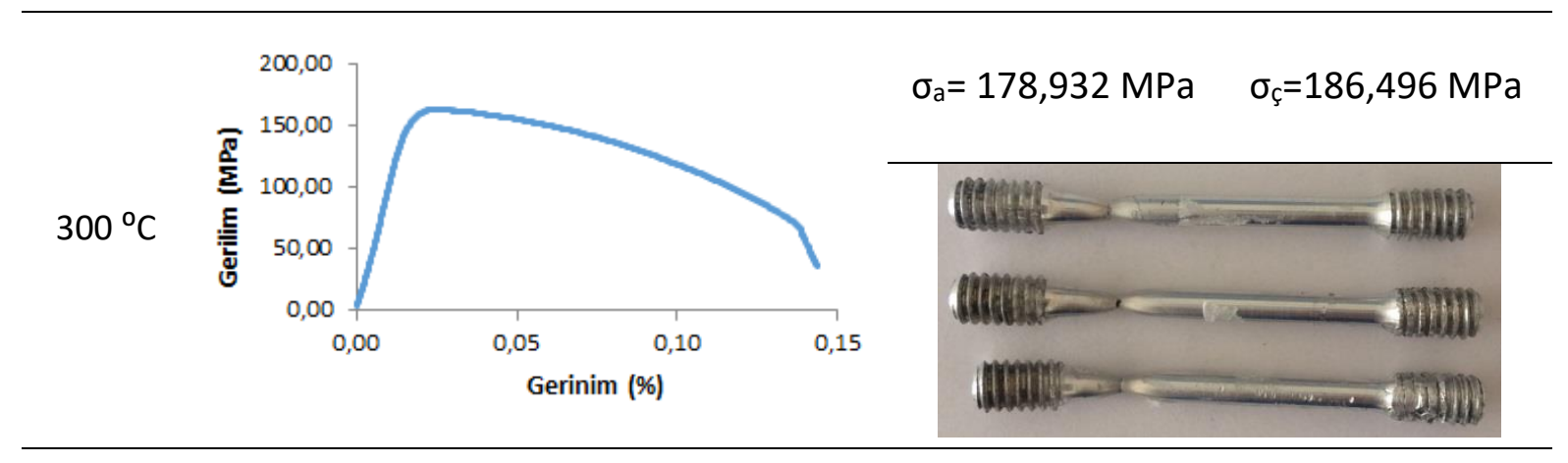

\section{B. REGRESYON ANALIZI}

Çalışma kapsamında ayrıca çekme testlerinin sonuçları regresyon analizleri ile incelenmiş, çekme ve akma dayanımlarının sıcaklıkla ilişkisi istatistiksel olarak değerlendirilmiştir. Analizlerden elde edilen grafikler ve denklemler Tablo 5'te verilmiştir. Elde edilen sonuçlar, ikinci derece ve üçüncü derece denklemlerin lineer denklemlere göre istatistiksel olarak daha anlamlı sonuçlar verdiğini göstermektedir. Analiz sonuçları incelendiğinde, sıcaklığın çekme $(\% 99,3)$ ve akma dayanımları $(\% 98,9)$ üzerinde yüksek oranda ve anlamlı bir etkisinin olduğu görülmüştür. Düşük sıcaklıklarda $\left(20^{\circ} \mathrm{C}\right.$ ve $\left.100^{\circ} \mathrm{C}\right)$ akma dayanımında belirgin bir değişiklik görülmezken (lineer davranış), yüksek sıcaklıklarda $\left(150^{\circ} \mathrm{C}, 200^{\circ} \mathrm{C}\right.$, $250^{\circ} \mathrm{C}$ ve $300^{\circ} \mathrm{C}$ ) önemli ölçüde azalma söz konusudur (üstel davranış). Çekme dayanımlarının sıcaklık arttıkça daha fazla azalma trendi gösterdiği görülmektedir. Akma ve çekme dayanımlarındaki bu değişimler Tablo 4 ’te verilen çekme diyagramları ile uyumluluk göstermektedir.

Tablo 5. Regresyon analizi sonuçları

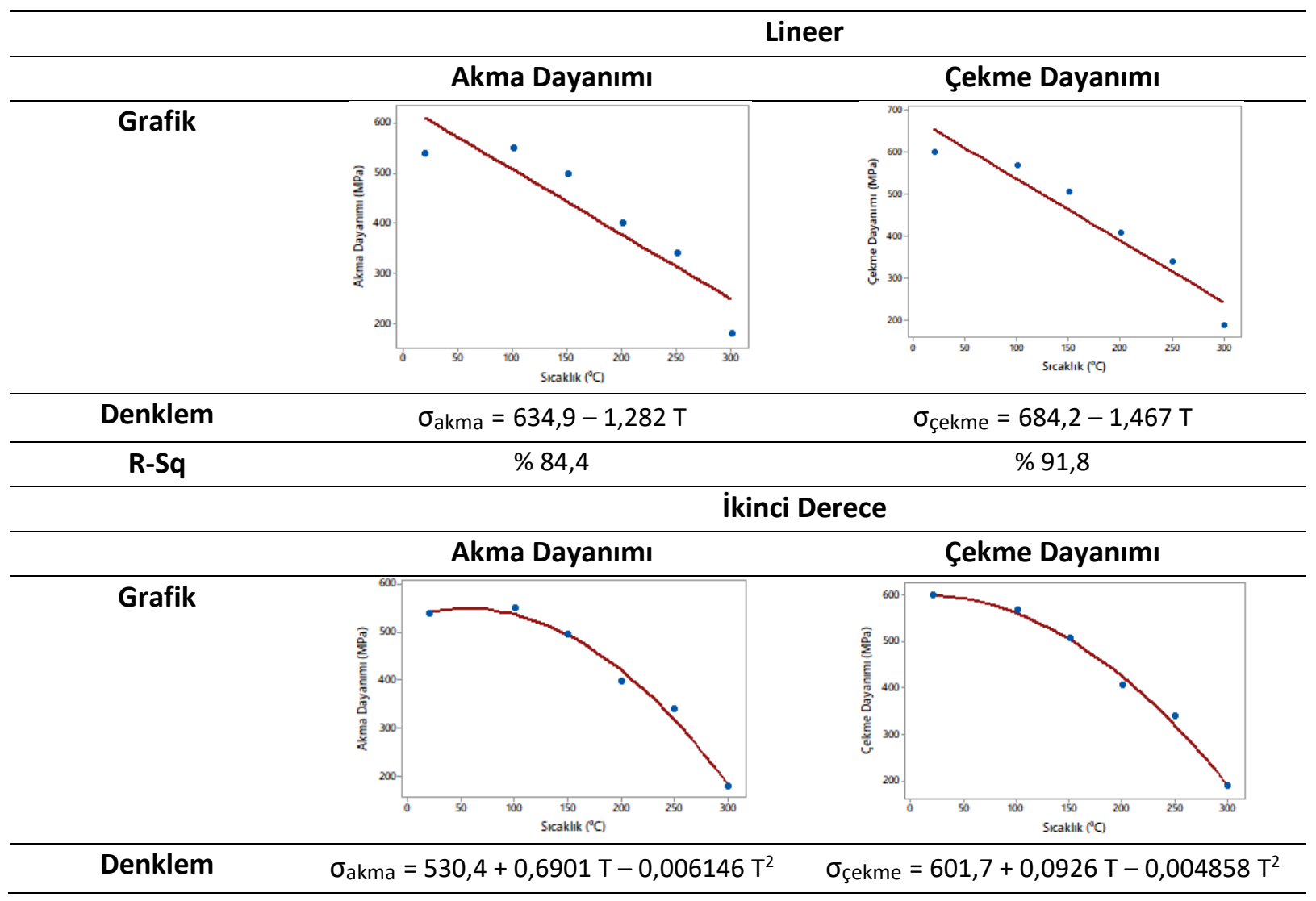




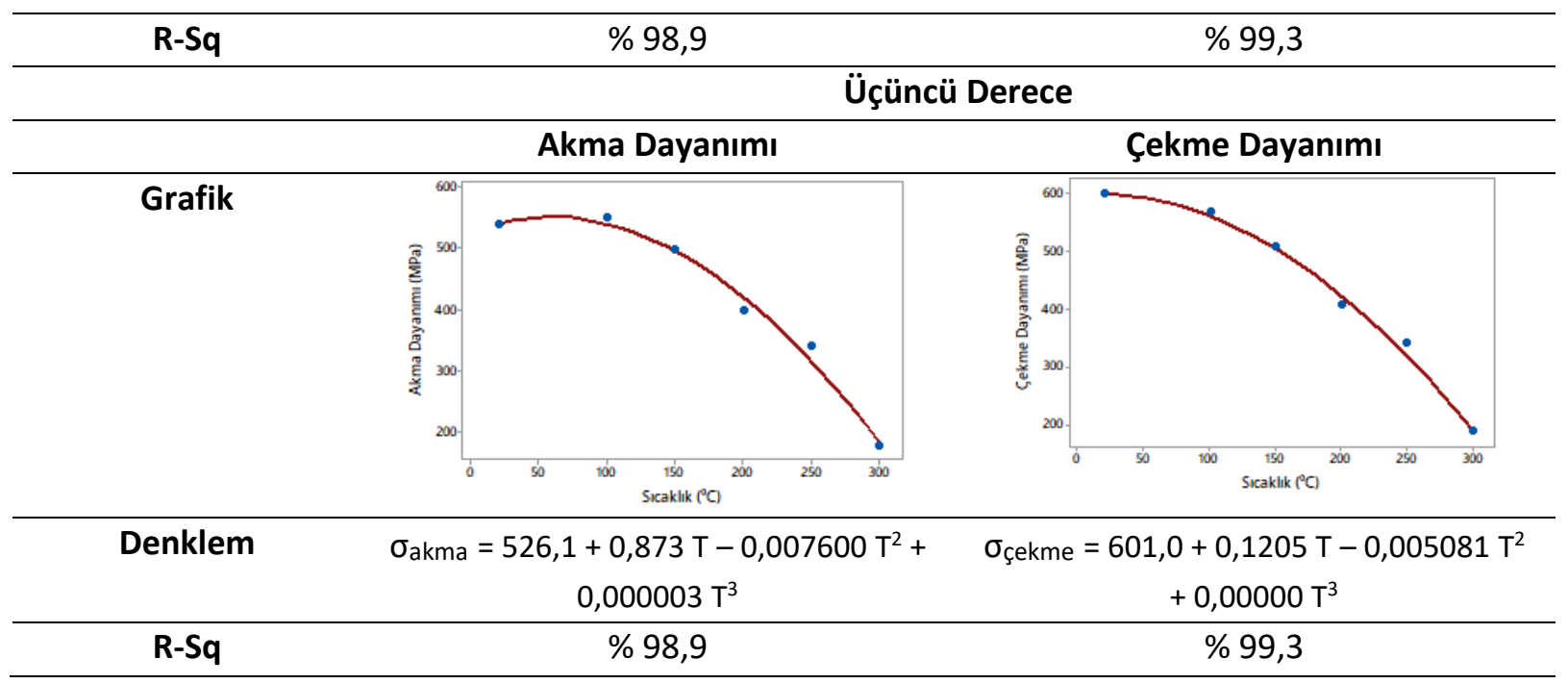

Çekme deneyinde etkili olan temel iki faktör sıcaklık ve şekil değiştirme hızıdır. Elde edilen regresyon değerleri (R-Sq) akma ve çekme dayanımı değerlerinin çok yüksek oranda sıcaklığa bağlı olarak belirlenebileceğini göstermektedir. Ara sıcaklık değerleri, deney yapmadan sadece sıcaklığa bağlı olarak çok düşük hata oranlarıyla tahmin edilebilir. Bu durum şekil değiştirme hızının etkisiz olduğu şeklinde bir hipotezi ortaya çıkarmaktadır. AA7075-T6 alaşımı için çok küçük şekil değiştirme hızı değişimlerinde anlamlı ve belirgin bir trend elde edilemeyeceği söylenebilir. Fakat, yüksek şekil değiştirme hızı değerlerinde ( $500-1500$ 1/s) elde edilen akma-çekme dayanımı değerleri şekil değiştirme hızının da akma-çekme dayanımı üzerinde anlamlı ve belirgin bir etkisi olduğunu göstermektedir [5]. Bu sebeple, elde edilen veriler, şekil değiştirme hızının çekme davranışı üzerinde anlamlı bir etkisi olmadığı şeklinde yorumlanmamalıdır.

\section{FRAGTOGRAFIK ANALIZ}

Kırılma mekanizmasına ilişkin bilgi edinebilmek için mikroskobik incelemeler yapılmıştır. Kırık yüzey incelemelerinde optik mikroskoba göre daha ayrıntılı bilgi verdiği için tarama elektron mikroskobu (SEM) tercih edilmiştir [10]. Şekil 4 ve Şekil 5'te farklı sıcaklıklarda (oda sıcaklığ $1,100^{\circ} \mathrm{C}, 150^{\circ} \mathrm{C}$, $200^{\circ} \mathrm{C}, 250^{\circ} \mathrm{C}, 300^{\circ} \mathrm{C}$ ) çekme testi yapılan numunelerin deformasyon bölgesinin SEM görüntüleri verilmiştir. Görüntüler incelendiğinde malzemenin kırılma yüzeylerinde mikro boşluklar meydana geldiği görülmüsşür. Yüksek sıcaklıklarda $\left(200^{\circ} \mathrm{C}, 250^{\circ} \mathrm{C}\right.$ ve $\left.300^{\circ} \mathrm{C}\right)$ düşük sıcaklıklara (oda sicaklığı, $100^{\circ} \mathrm{C}, 150^{\circ} \mathrm{C}$ ) nazaran çukurcuk sayısı artmış ve daha büyük çukurcuklar oluşmuştur. Bunun sebebi, sıcaklık arttıkça malzemenin daha fazla enerji absorbe etmesidir. İç yapıdaki artan enerjinin tane sınırlarında dislokasyon yoğunluğunu artırması kırılma yüzeylerinde daha büyük ve daha derin çukurların oluşmasına yol açmaktadır. Oluşan çukurcuk sayısının artması ve çukurcukların derinleşmesi malzemenin plastik deformasyonunu artırdığı için süneklik artmaktadır [5]. Çukurcuk oluşumu mekanizması için oluşturulan akış diyagramı Şekil 4'te verilmiştir. Bu durum Tablo 4'teki çekme diyagramı sonuçlarıyla uyumluluk göstermektedir. Bunun yanı sıra sıcaklık arttıkça deformasyon bölgesinde tane sınırlarının daha belirgin olduğu görülmektedir. Bu durum deformasyon bölgesinde meydana gelen çatlağın tane sınırlarında ilerlemesiyle açıklanabilmektedir. Şekil 5'te düşük sıcaklıklarda tane içi ilerleyen çatlak mekanizmasına ilişkin şematik görüntü verilmiştir. Ayrıca Şekil 5'te verilen SEM görüntüleri üzerinde, tane içi çatlak ilerlemesine ilişkin oluşan gerçek görüntüler işaretlenmiştir. Şekil 6'da ise tane sınırlarında ilerleyen çatlak kusuru için şematik görüntü verilmiş ve SEM görüntüleri üzerinde tane sınırlarında ilerleyen çatlak kusurları işaretlenmiştir. 


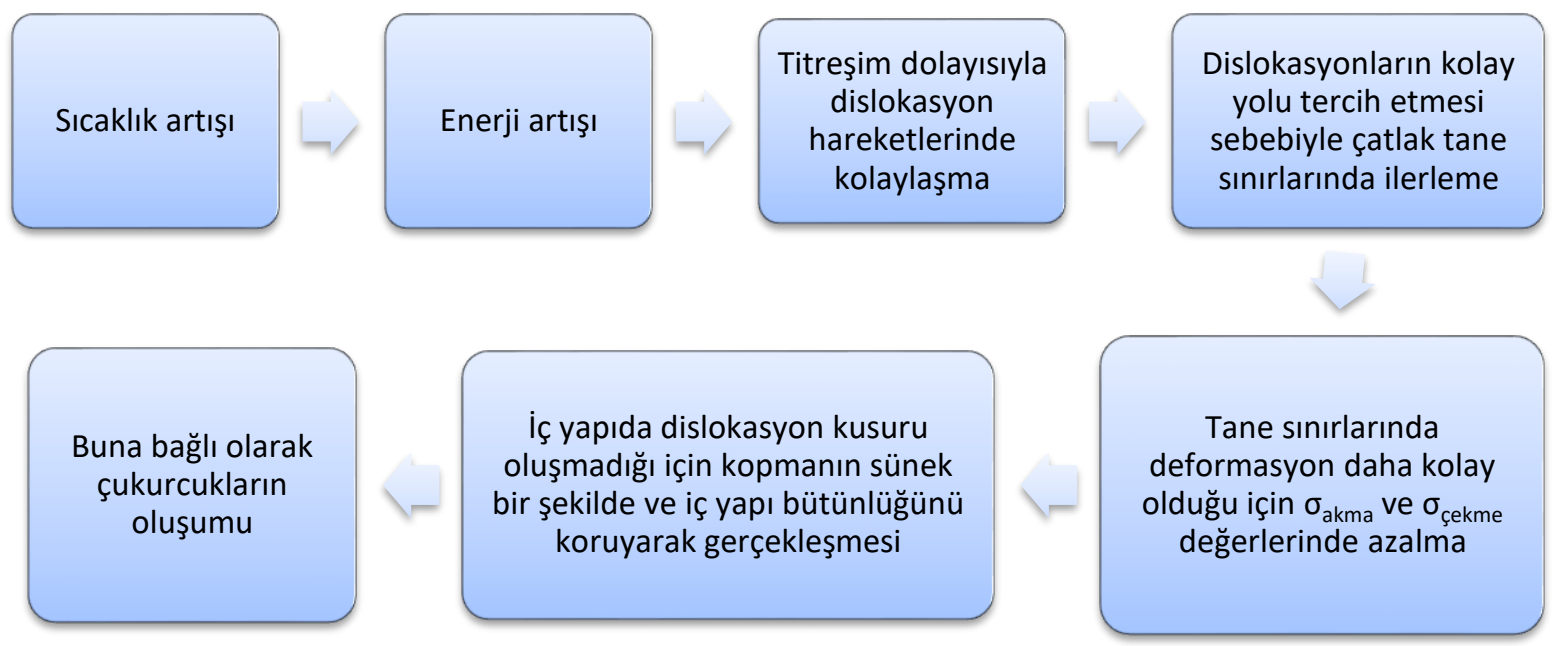

Şekil 4. Çukurcuk oluşumunun akış şeması

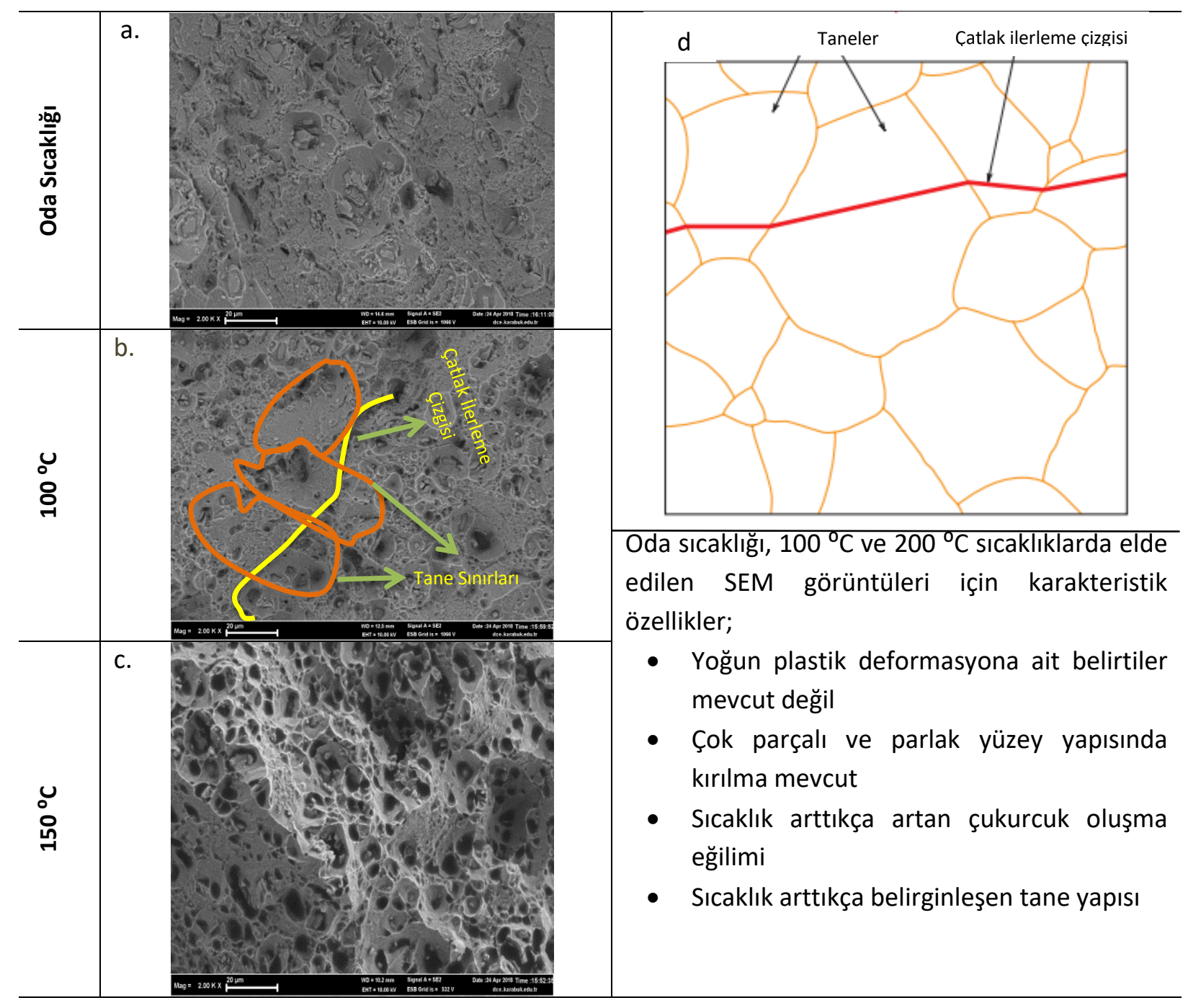

Şekil 5. SEM görüntüleri a) oda sıcaklığl b) $100{ }^{\circ} \mathrm{C}$ c) $150{ }^{\circ} \mathrm{C}$ d) tane içi kırılmanın şematik gösterimi [10] 


\section{SONLU ELEMANLAR ILE SAYISAL MODELLEME}

Çalı̧̧ma kapsamında AA7075-T6 alaşımı için çekme testinden elde edilen deneysel verilerin sonlu elemanlar yöntemi ile elde edilebilirliği araştırılmıştır. Tablo 6' da deneysel ve sayısal olarak elde edilen gerilme-birim uzama diyagramları verilmiştir. Sayısal olarak elde edilen grafikler 3 farklı ağ sayısına göre elde edilmiş ve her bir analiz sonucundan elde edilen grafikler Tablo 6'da gösterilmiştir. Ayrıca, oda sıcaklığı numunesi ile yüksek sıcaklık numuneleri geometrik olarak birbirinden farklı olduğu için farklı ağ sayılarında analizler yapılmıştır. Tablo 6'da verilen grafikler incelendiğinde, seçilen malzeme modelinin malzeme davranışını tanımlamada yetersiz kalması ve analizi gerçekleştiren bilgisayarın akma bölgesini analiz edecek yeterli donanıma sahip olmamasından dolayı grafiklerde elastik bölge elde edilememiştir. Elastik bölge, akma ve çekme mukavemet değerlerinin düşük olmasından dolayı sadece $300{ }^{\circ} \mathrm{C}$ koşulunda bir miktar modellenebilmiştir. Seçilen malzeme modeli, plastik bölgenin modellenmesinde bütün deney koşullarında yeterli ve anlamlı sonuç verebilmiştir. Tablo 6 incelendiğinde bütün sıcaklık koşulları için düşük ağ sayısında (3132 ve 6156 ağ) plastik bölgenin yeteri kadar modellenemediği fakat orta ve yüksek ağ sayılarında $(26169,57000,20196$ ve 34917 ağ) plastik davranışın yüksek benzerlik oranı ile modellenebildiği görülmektedir. Orta ve yüksek seviyedeki ağ sayıları arasında ise anlamlı bir farklılık bulunmadığı grafiksel olarak belirlenmiştir. Tablo 6'da verilen çekme diyagramlarında görülen bir diğer durum ise homojen şekil değiştirme bölgesinin daha doğru modellenebildiği, heterojen şekil değiştirme bölgesinde ise belirsizliğin bir miktar arttığıdır.

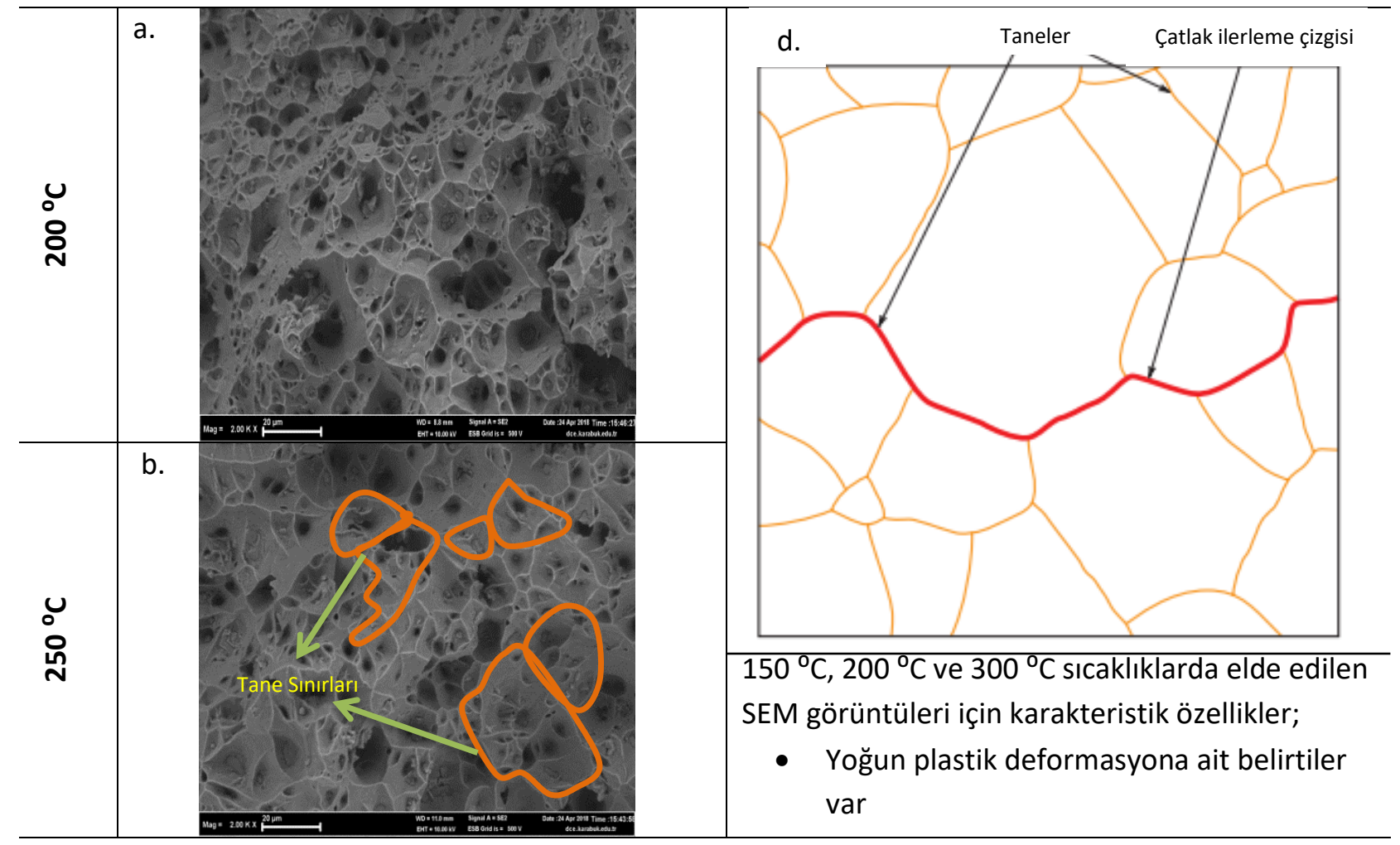




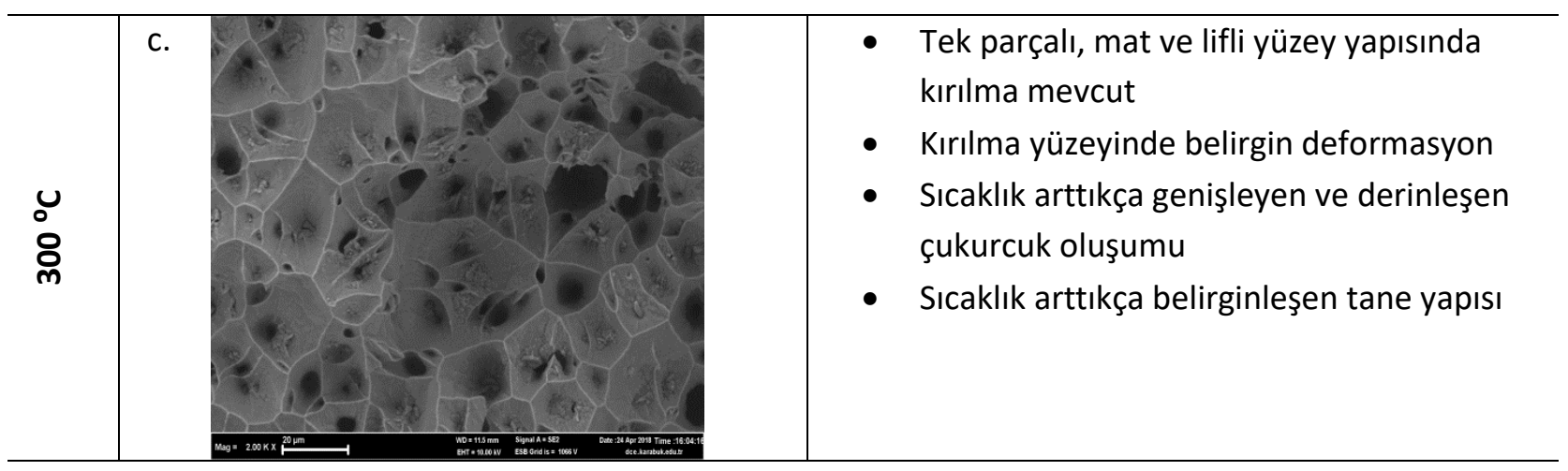

Şekil 6. SEM görüntüleri a) $200^{\circ} \mathrm{C} \mathrm{b)} 250{ }^{\circ} \mathrm{C}$ c) $300^{\circ} \mathrm{C}$ d) tane sınırlarında kırılmanın şematik gösterimi [10]

Simülasyon sonucu elde edilen bütün grafiklerde sıcaklık arttıkça çekme mukavemeti azalmaktadır. Fakat, $100{ }^{\circ} \mathrm{C}$ 'den $250{ }^{\circ} \mathrm{C}$ 'ye kadar olan sıcaklık artışında, çekme mukavemeti değerlerinde aynı oranda azalma görülürken, sıcaklık $250{ }^{\circ} \mathrm{C}$ 'den $300{ }^{\circ} \mathrm{C}$ 'ye çıktığında azalma oranı yaklaşık 2 katına çıkmaktadır. Nümerik olarak elde edilen bu sonuç deneysel olarak elde edilen sonuçlarla aynıdır (Tablo 6). Hem deneysel hem de sayısal olarak elde edilen grafikler; $100{ }^{\circ} \mathrm{C}$ sıcaklığa kadar AA7075-T6 malzemenin mekanik özelliklerinin sıcaklıkla önemli bir oranda değişim göstermediğini, $100{ }^{\circ} \mathrm{C}$ 'den $250^{\circ} \mathrm{C}$ 'ye kadar lineer azalan bir trendle mekanik özelliklerin değiştiğini, $300{ }^{\circ} \mathrm{C}$ sıcaklıkta ise mekanik değerlerin ciddi oranda düştüğünü göstermektedir. Sonlu elemanlar programında elde edilen numune görüntüleri de deneysel sonuçları desteklemektedir (Şekil 7). Şekil 7'ye göre oda sıcaklığında elde edilen numune görüntüsü yoğun gerilmenin varlığını gösterirken, sıcaklık arttıkça elde edilen numune görüntülerinde gerilmenin azaldığı renk analizi ile anlaşılmaktadır. Ayrıca Şekil 7'de sıcaklık arttıkça sünek deformasyon davranışının arttı̆gı ve Tablo 4'te verilen gerçek deney numuneleriyle benzer geometrik yapının oluştuğu görülmektedir.

Tablo 6. Sonlu elemanlar programı ile elde edilen çekme diyagramları

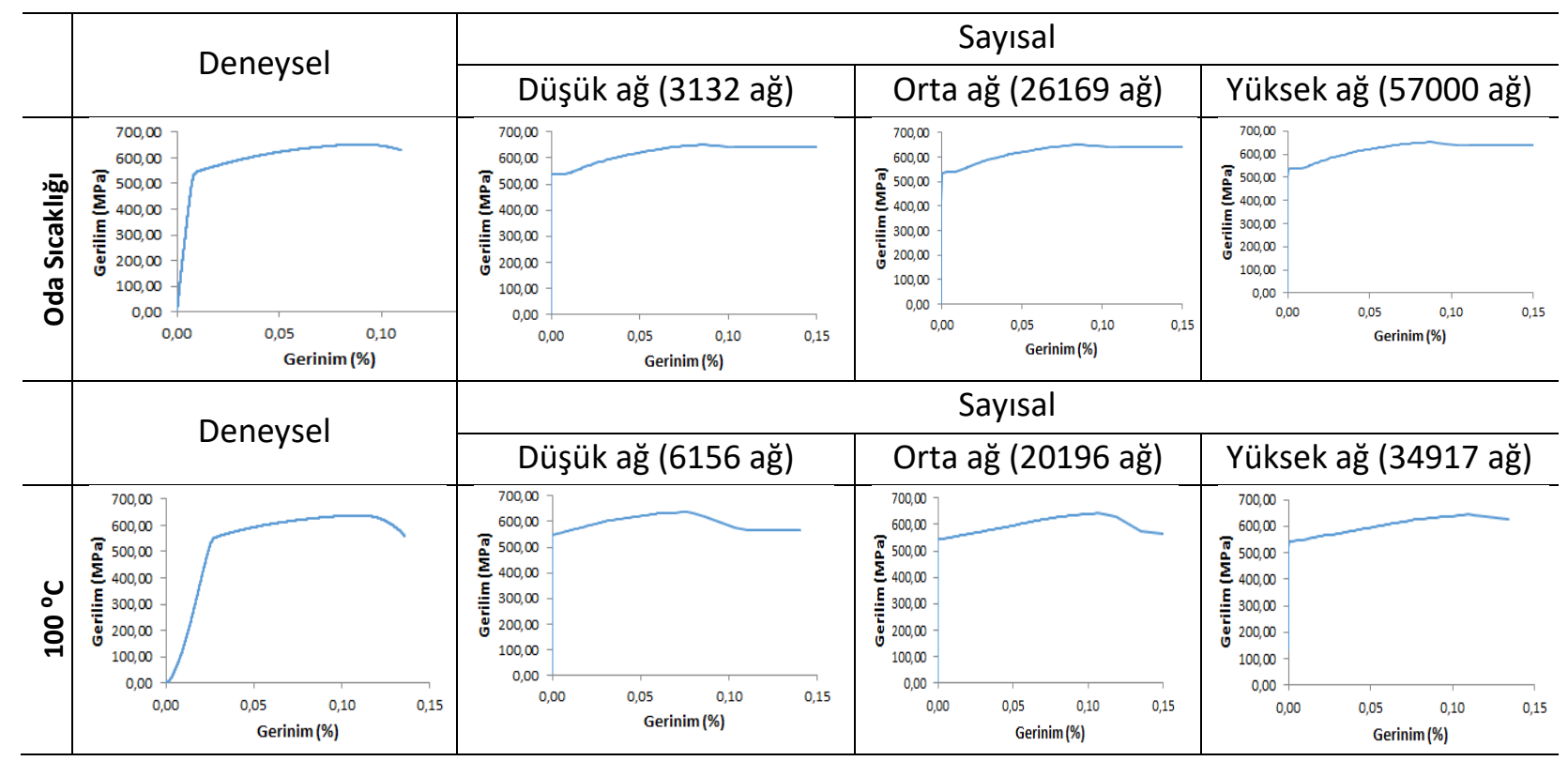



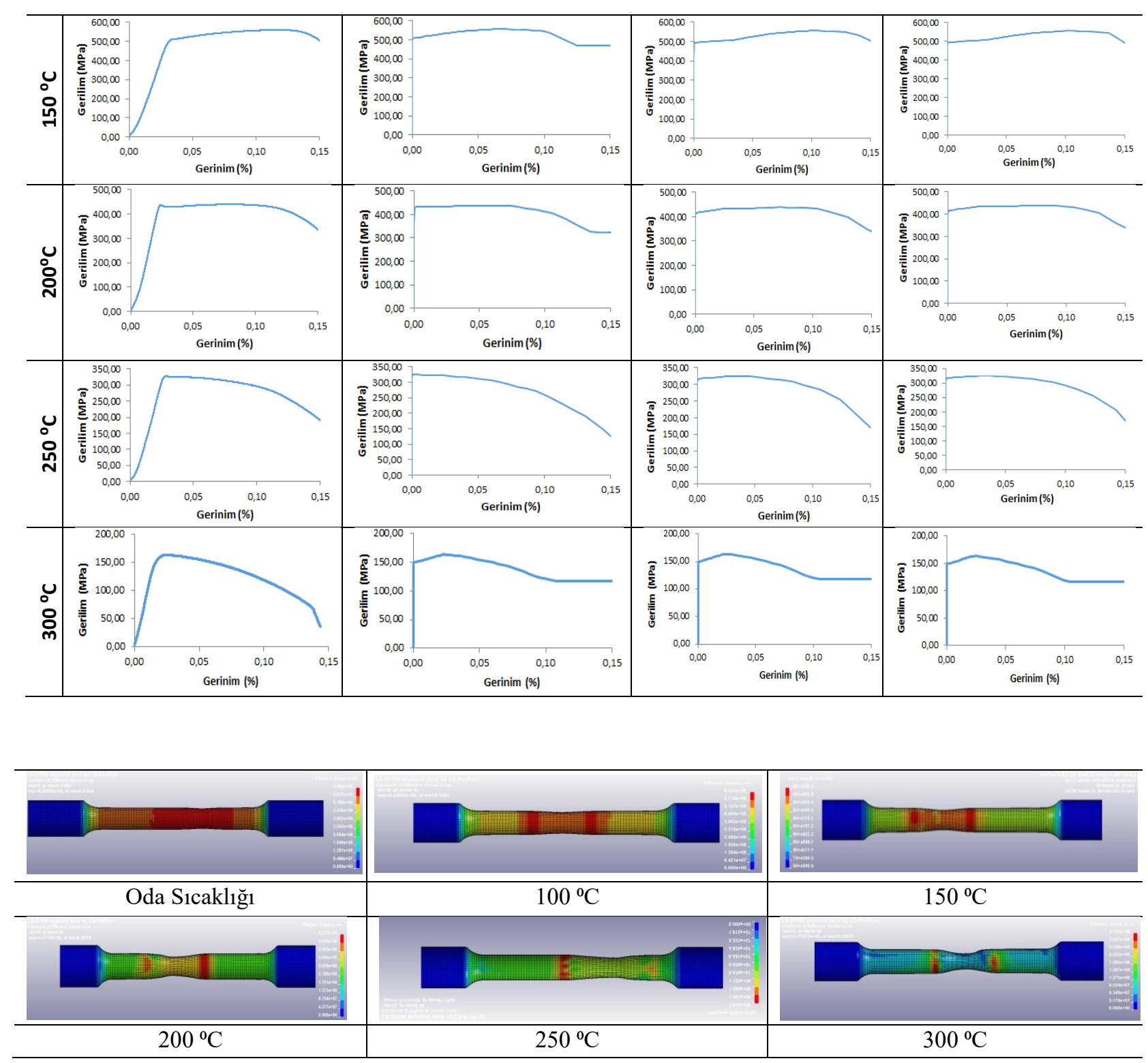

Şekil 7. Sonlu elemanlar programıla elde edilen numune görüntüleri

\section{SONUCCLAR}

AA7075-T6 alüminyum alaşımının farklı sıcaklıklardaki çekme davranışının incelendiği bu çalışmada aşağıdaki sonuçlar elde edilmiştir:

- Farklı sıcaklıklarda çekme testine tabi tutulan numuneler incelendiğinde, düşük sıcaklıklarda teste tabi tutulan numunelerin gevrek, yüksek sıcaklıklarda teste tabi tutulan numunelerin sünek kırılmaya maruz kaldığı görülmüş̧ür. Bunun yanı sıra sıcaklık arttıkça akma ve çekme mukavemetleri sıcaklık değerine bağlı olarak farklı oranlarda azalmıştır.

- Uygulanan çekme testlerinin istatistiksel olarak değerlendirilebilmesi için regresyon denklemleri elde edilmiştir. İncelenen regresyon analizlerine göre, düşük sıcaklıklarda akma mukavemeti değerlerinde 
belirgin bir değişiklik görülmezken, yüksek sıcaklıklarda önemli bir azalma söz konusudur. Çekme mukavemetleri ise sıcaklık arttıkça azalmaktadır.

- Kırılma mekanizmasına ilişkin bilgi edinebilmek için deformasyon bölgeleri mikroskobik olarak incelenmiş ve SEM görüntüleri alınmıştır. Görüntüler incelendiğinde, düşük sıcaklıklarda çok parçalı ve tane içi kırılma mevcutken, yüksek sıcaklıklarda tek parçalı ve tane sınırlarında kırılma mevcuttur. Sıcaklık arttıkça kırılma yüzeylerinde plastik deformasyonun artması sebebiyle çukurcuk sayısı ve derinliğinin arttığı görülmüştür.

- Çekme testinden elde edilen deneysel verilerin sonlu elemanlar ile elde edilebilirliği araştırılmıştır. Sonlu elemanlar yöntemi ile elde edilen grafiklerde elastik bölge, malzeme modelinin yetersizliği ve donanımsal eksiklik sebebiyle yeterince modellenememiştir. Seçilen malzeme modeli ile plastik bölgenin orta ve yüksek ağ sayılarında yüksek benzerlik ile modellenebildiği görülmüştür.

- Gerçekleştirilen analizler genel olarak, $100{ }^{\circ} \mathrm{C}$ sıcaklığa kadar AA7075-T6 malzemenin mekanik özelliklerinin sıcaklıkla önemli bir oranda değişim göstermediğini, $100^{\circ} \mathrm{C}$ 'den $250^{\circ} \mathrm{C}$ 'ye kadar lineer azalan bir trendle mekanik özelliklerin değiştiğini, $300{ }^{\circ} \mathrm{C}$ sıcaklıkta ise mekanik değerlerin ciddi oranda düştügünü göstermektedir.

- Sonlu elemanlar programı ile elde edilen numune görüntülerinin üzerindeki renk dağılımlarına göre; oda sıcaklığı numunesi üzerinde yoğun gerilmenin mevcut olduğu, sıcaklık arttıkça numunelerin üzerinde gerilmenin azaldığı anlaşılmaktadır. Ayrıca sonlu elemanlar görüntüleri, gerçek deneyler ile örtüşen şekilde, numunelerin sıcaklık artışıyla sünek kırılma eğiliminde olduğunu göstermektedir.

\section{$\underline{\text { V. KAYNAKLAR }}$}

[1] S.Toros, F. Ozturk, I. Kacar, "Review of Warm Forming of Aluminum-Magnesium Alloys",Journal of materials processing technology, c.207 s. 1-3, ss. 1-12, 2008.

[2] W. S. Lee, W. C. Sue, C. F. Lin, C. J. Wu, "The Strain Rate and Temperature Dependence of the Dynamic Impact Properties of 7075 Aluminum Alloy," Journal of Materials Processing Technology, c.100, s.1-3, ss. 116-122, 2000.

[3] M. R. Rokni, A. Zarei-Hanzaki, A. A. Roostaei, H. R. Abedi, "An Investigation Into The Hot Deformation Characteristics of 7075 Aluminum Alloy," Materials \& Design, c.32, s.4, ss. 2339-2344, 2011.

[4] T. Dokšanović, I. Džeba, D. Markulak, "Variability of Structural Aluminium Alloys Mechanical Properties," Structural Safety, c.67, ss. 11-26, 2017.

[5] R. Bobbili, V. Madhu, A. K. Gogia, "Tensile Behaviour of Aluminium 7017 Alloy at Various Temperatures and Strain Rates," Journal of Materials Research and Technology, c. 5, s.2, ss. 190-197, 2016. 
[6] K. Chen, H. Liu, Z. Zhang, S. Li, R. I. Todd, "The Improvement of Constituent Dissolution and Mechanical Properties of 7055 Aluminum Alloy by Stepped Heat Treatments," Journal of Materials Processing Technology, c.142, s.1, ss. 190-196, 2003.

[7] D. Li, A. Ghosh, "Tensile Deformation Behavior of Aluminum Alloys at Warm Forming Temperatures" Materials Science and Engineering: A, c.352, s.1-2, ss. 279-286, 2003.

[8] H. E. Hu, L. Zhen, L. Yang, W. Z. Shao, B. Y. Zhang, "Deformation Behavior and Microstructure Evolution of 7050 Aluminum Alloy During High Temperature Deformation," Materials Science and Engineering: A, c.488, s.1-2, ss. 64-71, 2008.

[9] M. H. Cetin, A. Ugur, O. Yigit, H. Gokkaya, E. Arcaklioglu, "Development of Forming Temperature Curves for Warm Deep Drawing Process Under Non-Isothermal Conditions," Arabian Journal for Science and Engineering, c.4, s.9, ss. 2763-2784, 2015.

[10] W. D. Callister, D. G. Rethwisch, Malzeme Bilimi ve Mühendisliği, 8. bask1, İstanbul, Türkiye: Nobel Akademik Yayıncılık, 2011, böl. 8, ss. 240-241. 